\title{
Micro-machinability of nanoparticle-reinforced Mg-based MMCs: an experimental investigation
}

\author{
Xiangyu Teng ${ }^{1} \cdot$ Dehong Huo $^{1} \cdot$ Eugene Wong $^{1} \cdot$ Ganesh Meenashisundaram $^{2}$. \\ Manoj Gupta ${ }^{2}$
}

Received: 13 November 2015 / Accepted: 4 March 2016 / Published online: 19 March 2016

(C) The Author(s) 2016. This article is published with open access at Springerlink.com

\begin{abstract}
As a composite material with combination of low weight and high engineering strength, metal matrix composites (MMCs) have been utilised in numerous applications such as aerospace, automobile, and bioengineering. However, MMCs are recognised as difficult-to-cut materials due to their improved strength and high hardness of the reinforcing particles. This paper presents an experimental investigation on micro-machinability of Mg-based MMCs reinforced with Ti and $\mathrm{TiB}_{2}$ nano-sized particles. The tool wear of AlTiN-coated micro-end mills was investigated. Both abrasive and chip adhesion effect were observed on the main cutting edges, whilst the reinforcement materials and volume fraction play an important role in determining the wear type and severity. The influence of cutting parameters on the surface morphology and cutting force was studied. According to analysis of variance (ANOVA), depth of cut and spindle speed have significant effect on the surface roughness. The specific cutting energy, surface morphology and the minimum chip thickness was obtained and characterised with the aim of examining the size effect. Furthermore, higher cutting force and worse machined surface quality were obtained at the small feed per tooth ranging from 0.15 to $0.5 \mu \mathrm{m} /$ tooth indicating a strong size effect. Overall, $\mathrm{Mg} / \mathrm{TiB}_{2} \mathrm{MMCs}$ exhibit better machinability.
\end{abstract}

Dehong Huo

dehong.huo@newcastle.ac.uk

1 School of Mechanical and Systems Engineering, Newcastle University, Newcastle Upon Tyne NE7 7QH, UK

2 Department of Mechanical Engineering, National University of Singapore, Singapore, Singapore 119077
Keywords Micro-milling $\cdot$ Micro-machinability $\cdot$ MMCs · Nano-reinforcements · Tool wear · Surface morphology · Cutting force $\cdot$ Size effect

\section{Introduction}

With the increasing demands on engineering materials with miniaturised sizes, low weight and superior mechanical properties in numerous areas [1], metal matrix composites materials have been developed and widely used in various areas such as the aerospace, automobile, electronics and bioengineering, thanks to their enhanced stiffness, strength, fracture toughness and reduced density when compared to their substrate material. Among MMCs materials, micro-sized particulate MMCs attract more attention from both industries and academia than fibre reinforced MMCs, as the former category exhibits higher ductility and lower anisotropy [2]. With the development of materials science, it has been reported that MMCs reinforced with small volume fraction of nano-sized particles could produce even superior results in mechanical properties than those reinforced with micro-sized particles [3-5].

The MMC components are normally fabricated in near net shapes; however, conventional machining, such as turning, milling and drilling is necessary to achieve desired accuracy and produce complex features. The mechanical properties of MMCs are improved significantly due to the hard reinforcement materials such as ceramics or metallic particles. Therefore, improved mechanical properties and its nature of heterogeneous structure make MMCs a very difficult-to-cut material. Numerous research have been carried out on conventional machining of a variety of metal matrix composites in the past two decades. However, little publication regarding 
the micro-machinability for MMCs reinforced with nanosized particles can be found.

This paper aims to investigate the influence of cutting parameters on the cutting force and surface morphology in micromachining of magnesium-based MMCs reinforced with two types of nano-sized particles, namely, titanium (Ti) and titanium diboride $\left(\mathrm{TiB}_{2}\right)$, as well as study the size effect and the minimum chip thickness according to the specific cutting energy and surface morphology at different feed per tooth. Moreover, the tool wear behaviour was evaluated. Additionally, a mechanistic model was established to predict the cutting force during machining. The experiment results presented an attempt to fill the gap and provide a comprehensive understanding on the micro-machinability of Mg-based MMCs reinforced with nano-reinforcements.

\subsection{Overview of Mg-based metal matrix composites (MMCs) materials}

Miniaturised structural components made of Mg-based MMCs materials have become a promising candidate in various applications due to its light weight, high wear resistance and especially biocompatibility. $\mathrm{Mg}$ alloys offers a high strength to mass ratio, where it is $35 \%$ lighter than aluminium alloy and approximately over four times lighter than steel [6]. The density of magnesium alloys and polymers is similar but the former possesses better mechanical and physical properties as shown in Table 1. The enhanced mechanical properties as a result of nano-sized particles addition can be mainly attributed to the efficient dispersion strengthening effects as while as the non-basal cross-slip activation induced by the variation in fracture model and reduced tensile-compression yield asymmetry. For the reinforcements, $\mathrm{Ti}$ and $\mathrm{TiB}_{2}$ have been chosen as the metallic and ceramic reinforcement, respectively. Because of desired properties of $\mathrm{TiB}_{2}$ such as high melting point, hardness, chemical inertness, low density and excellent resistance to wear, it is recognised as one of the best candidates of reinforcement for Mg MMCs [7, 8]. In addition, $\mathrm{TiB}_{2}$ has a crystal lattice coherent with that of the Mg matrix [9]. It has been reported that, titanium (Ti) is a material with high hardness and strength, and according to the Ti-Mg binary

Table 1 Comparison of general properties between $\mathrm{Mg}$ alloys and polymers (polycarbonate)

\begin{tabular}{lll}
\hline & Cast magnesium alloy & Polycarbonate \\
\hline Density $\left(\mathrm{kg} / \mathrm{m}^{3}\right)$ & $1750-1870$ & $1140-1210$ \\
Young's modulus $(\mathrm{GPa})$ & $42-47$ & $2-2.44$ \\
Yield strength $(\mathrm{MPa})$ & $70-215$ & $59-70$ \\
Tensile strength $(\mathrm{MPa})$ & $119-283$ & $60-72.4$ \\
Hardness (HV) & $35-90$ & $17.7-21.7$ \\
\hline
\end{tabular}

phase diagram, there is no formation of intermetallic compound between them [10]. Therefore, the particle phase of Ti could be reinforced into matrix material stably without chemical reaction.

\subsection{State-of-the-art shaping processes for MMCs and tool wear issues}

Several attempts on the fabrication of MMCs components using electro discharge machining (EDM) and laser machining have been made. During electro discharge machining of MMCs, the recast layer, surface waviness and blisters can be generated on machined surface, which are contributed by the ceramic particles removed by thermal spalling because of the plasma collapse at the time of pulse off [11]. Moreover, the surface finish is found to be relatively poor and the microstructure and mechanical properties are changed due to the high heat generated during the laser machining [12]. On the other hand, conventional machining is considered to be a more effective method to manufacture MMCs parts compared to other methods due to its high accuracy and good surface finish. However, the heterogeneous structure and high abrasiveness particles make it a difficult-to-cut material. It has been reported that, the significant damage mode that affects the tool performance are cracking and debonding of the reinforcement particles embedded in the matrix material [13]. Severe tool wear and reduction in accuracy resulting from direct contact between the cutting edge and particles which act as large number of small cutting edges were found during the machining process. A large number of research related to conventional machining of metal matrix composites have been carried out. Kannan et al. [13] studied the deformation behaviour for the strain-hardened matrix materials and its relationship with cutting force during orthogonal machining. They stated that the variation in the average dislocation density can be characterised as one of the main factor that affect the cutting force, and it is determined by variation in size and volume fraction of reinforcement and cutting parameters. Du et al. [14] investigated the chip formation process in the millgrinding of $\mathrm{SiC}_{\mathrm{p}} / \mathrm{Al}$ MMCs. A basic physical cutting model is employed to describe the chip formation mechanism. The thermal load acting on machining tool, cutting tool and workpiece in turning of $\mathrm{Al} / \mathrm{SiC}$ MMCs was studied by Aurich et al. [15]. They found that the Al MMCs undergo a higher thermal load than non-reinforced Al workpiece, as well as thermal load decreases when increase the feed rate or cutting speed.

The hard reinforcements embedded in the matrix materials bring a tremendous challenge in the machining of MMCs and lead to a very short tool life. The hard reinforcements which are separated from the substrate slide over the cutting edge during machining, consequently contribute to the amount of tool wear [16]. The tool wear modes affecting the machining performance can be generally classified as abrasive wear, 
chipping on the cutting edge, fractures and fatigue as a result of both thermal and mechanical load $[16,17]$. In conventional machining, a lot of studies regarding the tool wear modes and mechanism during the process of MMCs materials can be found. Weinert and Lange [16] conducted investigation on short fibre reinforced MMCs. They classified the abrasive wear into micro-cutting, micro-fatigue, micro-ploughing and microcracking in terms the characteristic of wear patterns. It was observed that tool wear can be characterised by micro cutting in the case where the hardness of particles is larger than cutting tool, and the tool are abraded as microcracking and micro-fatigue in the inverse case. In addition, Ciftci et al. [18] examined the performance of CBN cutting tool in turning of $\mathrm{Al} / \mathrm{SiC} \mathrm{MMCs}$, it was found that tool wear was mainly characterised as flank wear and influenced by particles size. Since researchers found that chip adhesion plays an important role in determining the surface quality at high speed cutting, polycrystalline diamond (PCD) tool and its coating were studied and found that they exhibited an outstanding performance in machining of MMCs materials due to its high hardness and low chemical affinity with the MMCs materials [19]. Huang et al. [20] conducted drilling experiment on $\mathrm{Al} / \mathrm{SiC}_{\mathrm{p}}$ with high volume fraction (56\%). An extremely rapid flank wear was found on PCD drills and they concluded that the primary mechanism includes abrasive and adhesive wear. Muguthu et al. [21] found that PCD tool exhibited lower power consumption and higher wear resistance when compared to polycrystalline cubic boron nitride (PCBN) in turning of $\mathrm{Al} 2123 \mathrm{SiC}_{\mathrm{p}}$ MMCs. While the PCD tools represent an admirable performance in machining of MMCs, it increases the machining cost significantly due to its expensive manufacturing cost. As one of the most common coating materials used for cutting tools, AlTiN-coated tools exhibit several preponderances during machining of metallic materials such as low costs, high hardness, abrasion and temperature resistance and it also create an aluminium oxide layer during the cutting process which can increase oxidation resistance at high cutting speed $[22,23]$. On the other hand, very little studies related to the micromachining of MMCs using AlTiN coating tools were found.

In order to meet the increasing demands for the high precision and miniature components with superior mechanical properties, micromachining, as an emerging machining process, is attracting attention from both industry and academia. However, several critical issues in micromachining process including minimum chip thickness, cutting edge radius effect, and ploughing effect become prominent with the decreasing ratio of uncut chip thickness and cutting tool edge radius [24]. Meanwhile, little published research regarding to the investigation of micromachining especially micro-milling of MMCs with nano-reinforcements can be found. Liu [25] conducted a micro-milling experiment on $\mathrm{Mg} \mathrm{MMCs}$ with $\mathrm{SiC}$ reinforcement, it was found that increasing SiC nano-reinforcements' volume fraction could improve yield and fracture strength of MMCs and consequently results in an increased cutting force. Moreover, the cutting force profiles are not as smooth as those of pure $\mathrm{Mg}$ as a results of the existence of nanoparticles which influences the chip formation of $\mathrm{Mg}$ MMCs.

\section{Experimental setup}

\subsection{Machine tool}

Micromachining experiments were carried out on an ultraprecision desktop micromachine tools (MTS5R) which is fitted with a high speed spindle driven by a continuous power of $100 \mathrm{~W}(240 \mathrm{~V})$, with the rotation speed ranging from 20,000 to $80,000 \mathrm{rpm}$. It has the capability of using high feed rate and cutters with small diameter. These ultra-precision micromachine tools consists of three axes $(\mathrm{X}, \mathrm{Y}, \mathrm{Z})$ which are controlled by DC servo motors with smallest feed of $0.1 \mu \mathrm{m}$. Ultra-precision collets are fitted to clamp the microend mills to ensure the run out of spindle within $1 \mu \mathrm{m}$. Figure 1 shows the micromachining tool fitted with a Kistler cutting force dynamometer.

\subsection{Workpiece materials}

In this research, two specimens including $\mathrm{Mg}$-based MMC reinforced with 1.98 Vol.\% of nano-sized $\mathrm{Ti}$ and $\mathrm{TiB}_{2}$ reinforcements were used. $\mathrm{Mg}$ particles with a size range from 60 to $300 \mu \mathrm{m}$ and purity $\geq 98.5 \%$ (supplied by Merck, Germany) were used as the matrix material, and $\mathrm{Ti}$ and $\mathrm{TiB}_{2}$ with an average size of $50 \mathrm{~nm}$ were used as reinforcements. Pure magnesium powder was blended with the appropriate amount of reinforcements in a RETSCH PM-400 mechanical alloying machine at $200 \mathrm{rpm}$ for $1 \mathrm{~h}$. The homogenised powder mixtures of $\mathrm{Mg}$ and reinforcement were then cold compacted at a

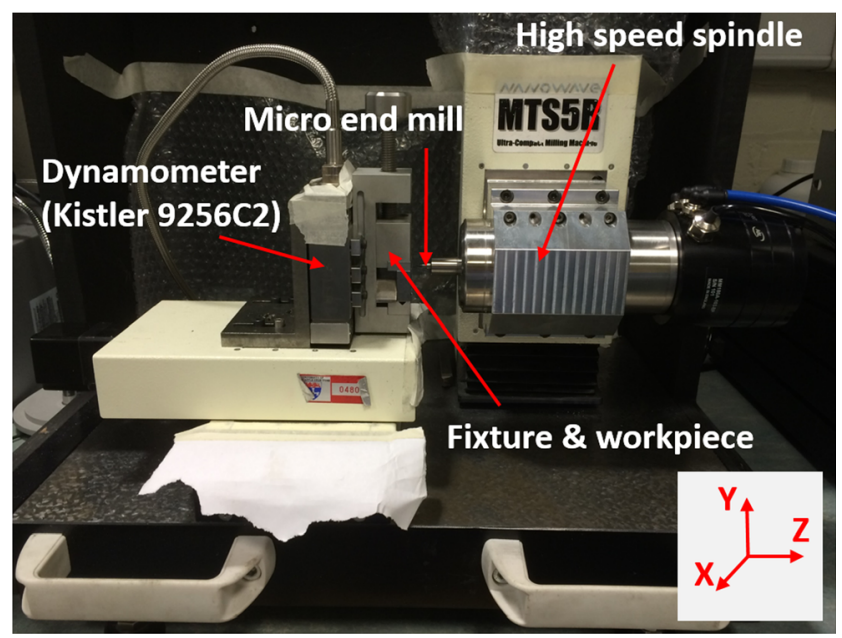

Fig. 1 Micromachine tool with the Kistler dynamometer 
Fig. 2 AlTiN-coated tungsten carbide micro-end mill with cutting edge radius measurement. a front view; $\mathbf{b}$ side view of endmill; $\mathbf{c}$ magnified view for the corner edge
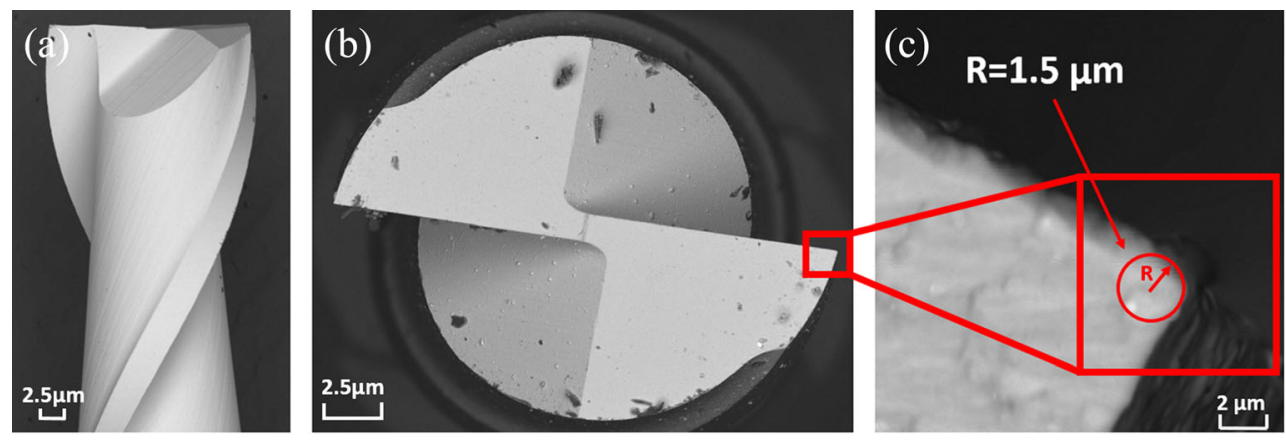

pressure of $1000 \mathrm{MPa}$ to form billets of $40 \mathrm{~mm}$ in height and $35 \mathrm{~mm}$ in diameter. Monolithic magnesium was compacted using the same parameters without blending. The compacted billets were sintered using hybrid microwave sintering at $640{ }^{\circ} \mathrm{C}$ in a $900 \mathrm{~W}, 2.45 \mathrm{GHz}$ SHARP microwave oven. The sintered billets were then soaked at $400{ }^{\circ} \mathrm{C}$ for $1 \mathrm{~h}$ and subsequently hot extruded at $350{ }^{\circ} \mathrm{C}$ using an extrusion ratio of 20.25:1 to obtain rods of $8 \mathrm{~mm}$ in diameter. Further details for the fabrication of the magnesium nanocomposites have been documented in earlier publication [26].

\subsection{Micro-end mills}

2-flutes AlTiN-coated tungsten carbide micro-end mills (Fig. 2) with tool diameter of $1 \mathrm{~mm}$ and shank diameter of $3 \mathrm{~mm}$ were utilised. In order to reduce tool deflection in the experiment, a relative large tool diameter was selected since a wider range of feed rates were used in this experiment. The geometry of all the new tools used in the experiment was examined by SEM before milling. The cutting edge radius was estimated to be $1.5 \mu \mathrm{m}$ by SEM measurement. Table 2 illustrates the geometries of micro-end mills used in this experiment.

\subsection{Experimental procedure}

To study tool wear behaviour, two new tools were used for each materials $\left(\mathrm{Ti}, \mathrm{TiB}_{2}\right)$. A piezoelectric dynamometer (Kistler 9256C2) was used to acquire the cutting force along the $\mathrm{X}, \mathrm{Y}$, and $\mathrm{Z}$ axis during the machining. The surface

Table 2 Micro-end mill specifications

\begin{tabular}{ll}
\hline Properties & Values \\
\hline Nominal diameter $(\mathrm{mm})$ & 1 \\
Number of flute & 2 \\
Helix angle ( ) & 25 \\
Flute length $(\mathrm{mm})$ & 1.5 \\
Rake angle ( ) & 0 \\
Clearance angle ( ) & 17 \\
Tool edge radius $(\mu \mathrm{m})$ & 1.5 \\
\hline
\end{tabular}

roughness of the bottom machined surface was measured using a Zygo white light interferometer (NewView 5020). In addition, the micrographs for each machined surface and the worn cutting tools were obtained using a scanning electron microscope (Hitachi TM3030). All observations on tool wear were made after same volume of removed materials. Two individual full slot (1 $\mathrm{mm}$ width and $5 \mathrm{~mm}$ length) micromilling experiments were conducted, respectively, on two types of Mg-based MMCs. Each machining condition was repeated once. Full factorial design was employed in the first experiment. Three controlled quantitative factors were used in this experiment, spindle speed $n(\mathrm{rpm})$, feed per tooth $f_{z}(\mu \mathrm{m} /$ tooth) and depth of cut $a_{p}(\mu \mathrm{m})$. Twenty-four slots milling with various cutting conditions (illustrated in Table 3) was used to study the effect of cutting parameters on the cutting force and surface roughness. Table 4 shows the cutting conditions in the second experiment; there are 16 slots milling with various feeds per tooth and constant depth of cut and spindle speed with the aim of investigating the specific cutting energy and size effect.

\section{Results and discussions}

\subsection{Tool wear}

According to the SEM images obtained in Fig. 3a-d, both abrasive and adhesion wear mode were observed during machining MMCs with nano-sized $\mathrm{TiB}_{2}$ and Ti particles. In the case of the endmill used in machining $\mathrm{Mg} / \mathrm{Ti}$ MMCs with 1.98 Vol.\%, Fig. 3c, d indicates that the chip adhesion effect is evident along the main and corner edge as a result of the interaction between the cutting tool and workpiece. The

Table 3 Cutting conditions for the first experiment

\begin{tabular}{lllll}
\hline Cutting parameters & Level 1 & Level 2 & Level 3 & Level 4 \\
\hline Spindle speed, $n(\mathrm{rpm})$ & 20,000 & 40,000 & 60,000 & N/A \\
Depth of cut, $a_{p}(\mu \mathrm{m})$ & 150 & 300 & N/A & N/A \\
Feed per tooth, $f_{z}(\mu \mathrm{m})$ & 1 & 2 & 3 & 4 \\
\hline
\end{tabular}


Table 4 Cutting conditions for the second experiment

\begin{tabular}{lllll}
\hline Exp No. & $\begin{array}{l}\text { Feed rate } \\
f_{t}(\mathrm{~mm} / \mathrm{min})\end{array}$ & $\begin{array}{l}\text { Spindle speed } \\
n(\mathrm{rpm})\end{array}$ & $\begin{array}{l}\text { Depth of cut } \\
a_{p}(\mu \mathrm{m})\end{array}$ & $\begin{array}{l}\text { Feed per tooth } \\
f_{z}(\mu \mathrm{m} / \text { tooth })\end{array}$ \\
\hline 1 & 4 & 40,000 & 150 & 0.05 \\
2 & 8 & 40,000 & 150 & 0.1 \\
3 & 12 & 40,000 & 150 & 0.15 \\
4 & 16 & 40,000 & 150 & 0.2 \\
5 & 24 & 40,000 & 150 & 0.3 \\
6 & 32 & 40,000 & 150 & 0.4 \\
7 & 40 & 40,000 & 150 & 0.5 \\
8 & 64 & 40,000 & 150 & 0.8 \\
9 & 88 & 40,000 & 150 & 1.1 \\
10 & 112 & 40,000 & 150 & 1.4 \\
11 & 136 & 40,000 & 150 & 1.7 \\
12 & 160 & 40,000 & 150 & 2 \\
13 & 240 & 40,000 & 150 & 3 \\
14 & 320 & 40,000 & 150 & 4 \\
15 & 400 & 40,000 & 150 & 5 \\
16 & 480 & 40,000 & 150 & 6 \\
\hline
\end{tabular}

increased degree of thermal softening of workpiece material in micro-milling with high cutting speed could be the main factor that caused the workpiece materials to stick on the cutting edge. The material properties of reinforcement (Ti) and matrix $(\mathrm{Mg})$ such as relatively low melting point and ductile structure might contribute to this phenomenon as well. It can be thought that the AlTiN-coated cutting tool exhibited a high propensity for work materials adhesion during cutting $\mathrm{Mg} / \mathrm{Ti}$ MMCs. Chip adhesion effect plays an important role in determining the cutting performance and tool life especially in micromilling process. Increasing amount of workpiece material will be stuck on the cutting edge due to chip adhesion effect, resulting in an increased cutting edge radius and consequently leading to an increased critical uncut chip thickness. Chip formation can only occur when an uncut chip thickness is above the critical chip thickness. The ploughing mechanism dominates the cutting process when the uncut chip thickness is less than the critical value. Ploughing mechanism can result in a deteriorative machined surface, higher cutting force and shorter tool life by increasing the friction and uneven stress distribution between the cutting tool and the workpiece, and this negative effect could be amplified in micro-milling process compared to conventional milling. As a result, the increased cutting edge radius caused by chip adhesion effect increases the value required to reach critical chip thickness, and the ploughing mechanism become more evident during cutting process.

According to Fig. 3a, c, the severity of chip adhesion effect on the cutting edge of the tool used in the cutting of $\mathrm{Mg} / \mathrm{TiB}_{2}$ MMCs was significantly less than that observed on the tool cutting edge used in $\mathrm{Mg} / \mathrm{Ti}$ MMCs. This could be explained in the view of mechanical properties of reinforcement materials. Due to the relatively high hardness and rigid body owned by $\mathrm{TiB}_{2}(3000 \mathrm{HV})$ particles, the particles which were separated from the matrix slide over the rake and flank face of the cutting tool, meanwhile a high dynamic load caused by the impacts of the reinforcements act on the cutting edge contributes to the amount of abrasive wear, as a consequence the chip adhered on the cutting edge was abraded off. This phenomena has not been be observed during cutting MMCs reinforced with Ti particle due to its much lower hardness (300 HV) when compared to $\mathrm{TiB}_{2}$.

As illustrated in Fig. 3b, d, cutting tool corner fracture can be observed after machining both $\mathrm{Mg} / \mathrm{Ti}$ and $\mathrm{TiB}_{2}$ MMCs. This type of fracture can be found during several studies related to tool wear in micro-milling of difficult-to-cut materials [26-28]. Consequently, the machining accuracy and surface finish could be affected.

The worn main cutting edge of endmill used to machine $\mathrm{Mg} / \mathrm{TiB}_{2}$ and $\mathrm{Mg} / \mathrm{Ti} \mathrm{MMCs}$ can be seen from Fig. 3a, c, respectively. The coating peeling off is more evident in $\mathrm{Mg} / \mathrm{TiB}_{2}$ than that in $\mathrm{Mg} / \mathrm{Ti}$ in terms of the area of coating peeling off along the main edges. During the cutting of MMCs materials, both mechanical load and thermal load can be induced on the cutting edge [16]. Mechanical load can be characterised as the high dynamic load impacting of particles with high hardness as aforementioned. The high local temperature generated due to the high cutting speed and the micro conduct between the particles and cutting edge could weaken the coating structure. Moreover, the high melting point $(3500 \mathrm{~K})$ and thermal conductivity of $\mathrm{TiB}_{2}$ particles assist this negative effect by leading large impact load acting on the tool coating. Additionally, the milling process is dynamically different as conventional turning, the chips are removed intermittently and consequently the cutting edge are subject to respective loads. This dynamics feature causes the fatigue on the cutting edge which is one of the factors that contributes to the amount of tool wear.

Two additional micro-milling experiments were conducted on same MMCs materials but with different reinforcement volume fraction of $0.97 \%$ with the aim of investigating the effect of volume fraction of reinforcement on tool wear. The volume fraction and size of reinforcements are known to play an important role in determining the cutting performance. Quan and Zhou [29] conducted conventional turning experiment on $\mathrm{SiC}$ particles reinforced MMCs. It was found that the severity of tool corner and flank wear would increase as increasing of volume fraction and particles size of the reinforcement. The difference of the severity of tool wear when cutting $\mathrm{Mg}$ based MMCs with different volume fraction can be found by comparing with the Fig. $3 \mathrm{a}$, c and Fig. $4 \mathrm{a}$, b. In the 
Fig. 3 SEM images of the worn AlTiN-coated tools used in $\mathbf{a}, \mathbf{b}$ machining $\mathrm{Mg} / \mathrm{TiB}_{2}$ with $1.98 \mathrm{Vol} . \%$; c, d Mg/Ti with $1.98 \mathrm{Vol} . \%$ and e, f new tool

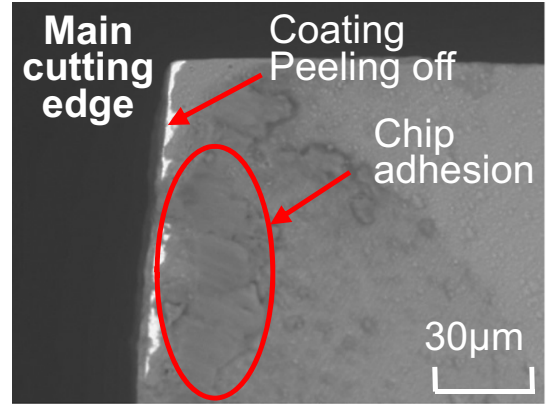

(a). $\mathrm{Mg} / \mathrm{TiB}_{2}$

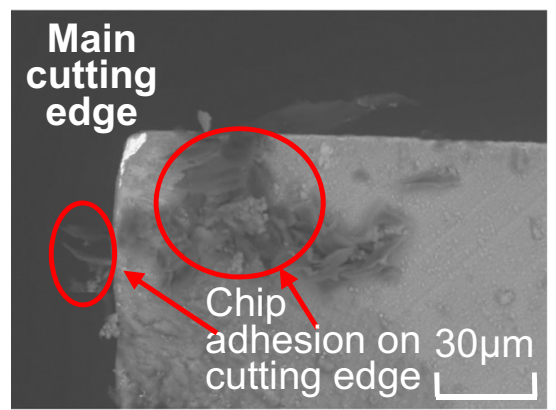

(c). $\mathrm{Mg} / \mathrm{Ti}$

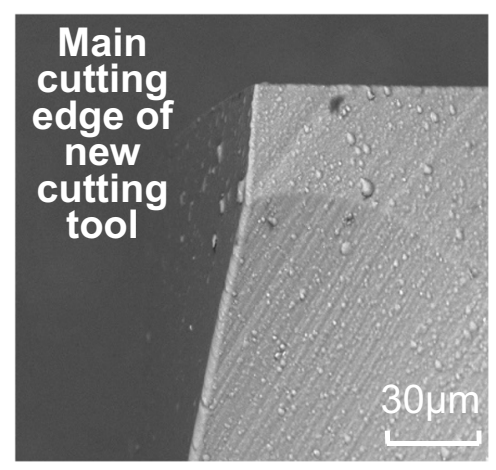

(e)

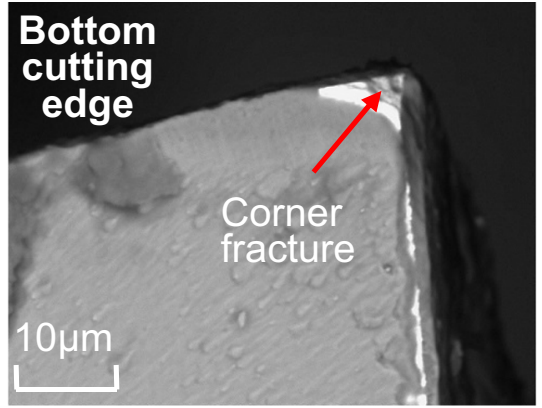

(b). $\mathrm{Mg} / \mathrm{TiB}_{2}$

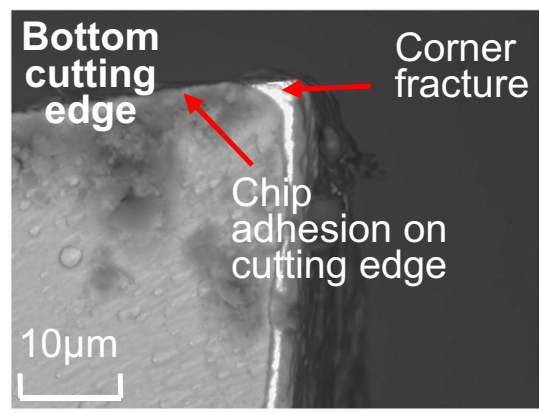

(d). $\mathrm{Mg} / \mathrm{Ti}$

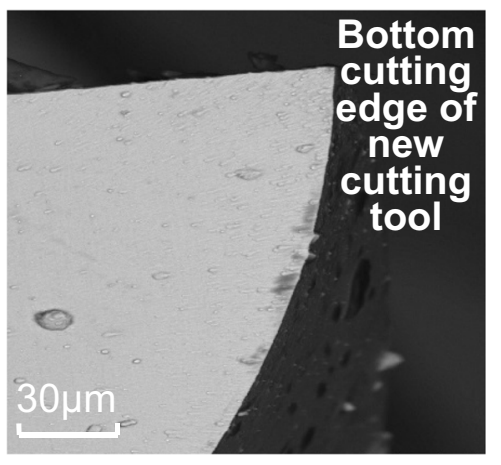

(f) case of cutting $\mathrm{Mg} / \mathrm{TiB}_{2}$ MMCs, a smaller area of coating peeling off can be found on the corner edge in the MMCs with lower volume fraction when compared to that with higher volume fraction. In the cutting of $\mathrm{Mg} / \mathrm{Ti}$ MMCs with lower volume fraction, coating peeling off was not observed on the cutting edge, and same as that used for cutting $\mathrm{Mg}$ /Ti MMCs with higher volume fraction, chip adhesion effect is still evident.

Fig. 4 SEM images of the worn AlTiN-coated tools used in machining. a $\mathrm{Mg} / \mathrm{TiB}_{2}$ with 0.97 Vol.\%. b Mg/Ti with 0.97 Vol.\%

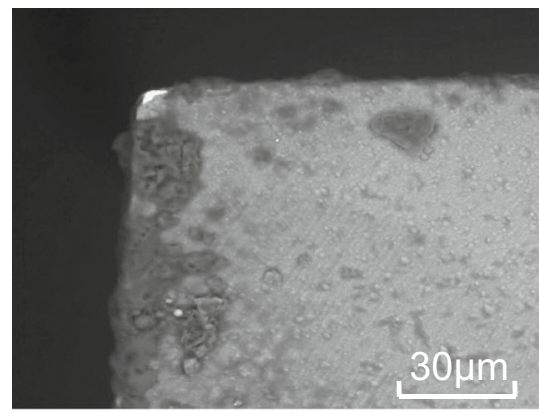

(a)

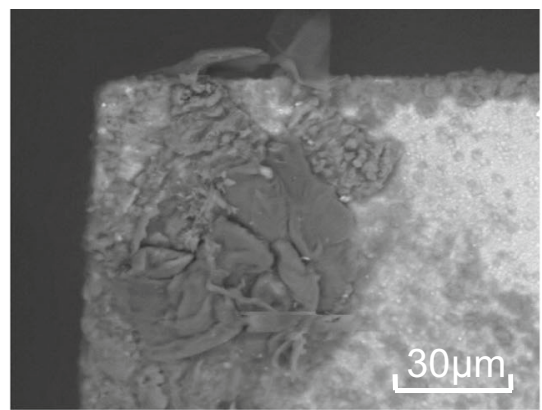

(b) 
Fig. 5 Main effects of cutting parameters on the surface roughness. a $\mathrm{Mg} / \mathrm{TiB}_{2} \mathrm{MMCs}$. b $\mathrm{Mg} / \mathrm{Ti} \mathrm{MMCs}$

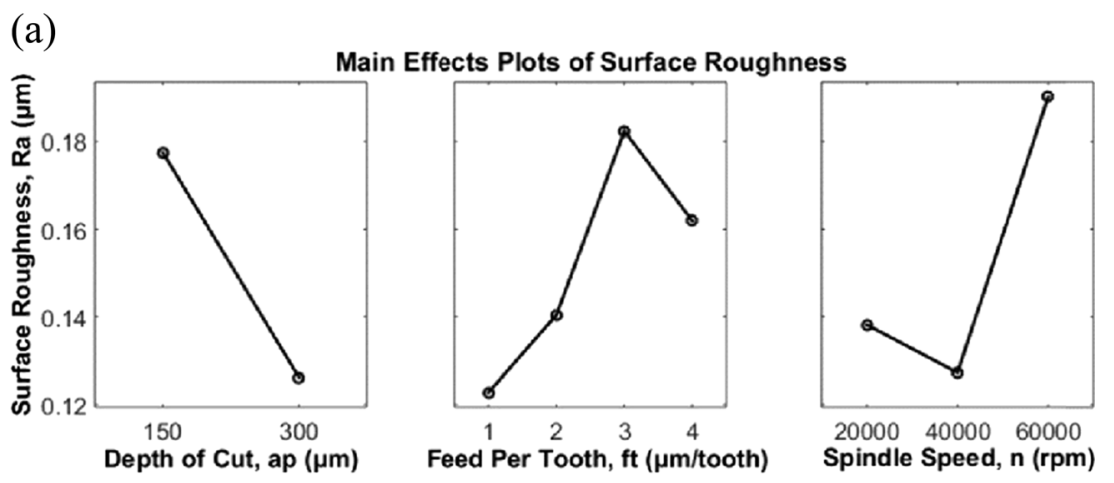

(b)

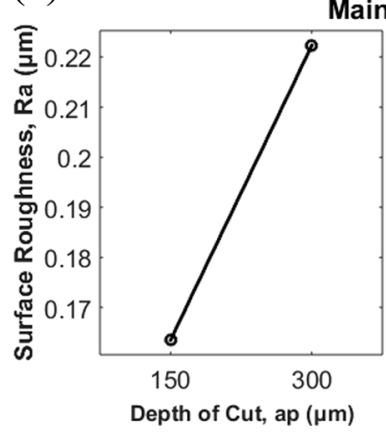

Main Effects Plots of Surface Roughness
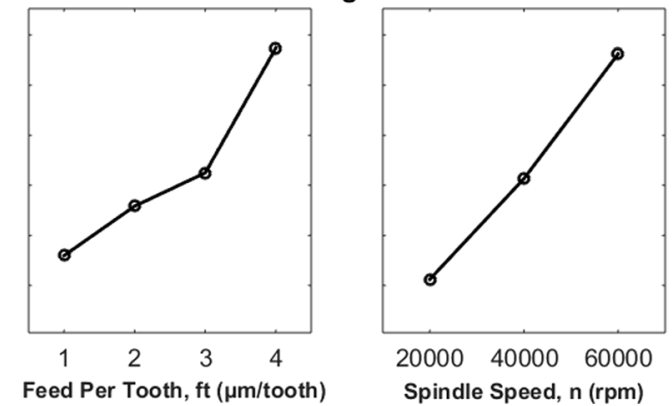

\subsection{Surface roughness}

The average surface roughness of the bottom machined surface of the micromachined slots was obtained. Three measurements on different position of each slot were carried out with the aim of reducing the measurement uncertainty and assessing repeatability. Mean value of Ra was used for analysis.

Main effects of cutting parameters on the surface roughness for $\mathrm{Mg} / \mathrm{TiB}_{2}$ and $\mathrm{Mg} / \mathrm{Ti} \mathrm{MMCs}$ were plotted in Fig. 5a, b, respectively. Unlike the inverse proportional variation trend of surface roughness with respect to spindle speed observed in the previous research conducted on the conventional turning of $\mathrm{Al} / \mathrm{SiC}$ and $\mathrm{Al} /$ $\mathrm{Cu}$-TiC MMCs [30, 31], a proportional relation was found between surface roughness and spindle speed for $\mathrm{Mg} / \mathrm{Ti}$ MMCs. This could be due to the continuous semi-circular tool marks which are known as side flow in turning, on machined surface in full slots milling as a result of squeeze between the corner edges of endmill and the material at the relatively small uncut chip thickness to cutting edge radius ratio in micro-milling. High heat was generated at high spindle speed of $20 \mathrm{k}$ $60 \mathrm{k} \mathrm{rpm}$ (linear speed $=10.46-31.4 \mathrm{~m} / \mathrm{s}$ ) and consequently soften the material which assists the formation of semi-circular tool marks. The surface roughness, however, was observed to decrease when increasing the spindle speed from 20,000 to $40,000 \mathrm{rpm}$, then increase rapidly when spindle speed increase to 60 ,
$000 \mathrm{rpm}$ for $\mathrm{Mg} / \mathrm{TiB}_{2} \mathrm{MMCs}$. Lower depth of cut should be selected to minimise the surface roughness in machining of $\mathrm{Mg} / \mathrm{Ti}$ MMCs. For machining $\mathrm{Mg}$ / $\mathrm{TiB}_{2}$ MMCs, however the higher depth of cut results in a lower surface roughness value and this tendency is contrary to micro-milling of metallic materials. An increase in feed per tooth from 1 to $3 \mu \mathrm{m} /$ tooth results in increase of surface roughness values in both materials. Overall, the machined surface quality of $\mathrm{Mg} / \mathrm{TiB}_{2}$ MMCs was superior than that of $\mathrm{Mg} / \mathrm{Ti}$ MMCs in terms of surface roughness value. This might be contributed to the higher cutting force induced in cutting process of $\mathrm{Mg} / \mathrm{Ti}$ MMCs (will be discussed in the cutting force section as a result of chip adherence effect).

ANOVA for the first trial in micromachining experiments of two materials was carried on the surface roughness to isolate main effects of each source of variations and determine effects of interactions (Table 5 and 6). It can be concluded that the depth of cut and spindle speed have significant influence on surface roughness in both materials. The contribution ratio for the spindle speed and depth of cut is 33 and $29 \%$ for machining $\mathrm{Mg} / \mathrm{TiB}_{2}$ MMCs, 19 and $49 \%$ for the machining $\mathrm{Mg} / \mathrm{Ti}$ MMCs. The interactions between two cutting parameters are found to be not significant to the results.

\subsection{Cutting force}

Measurement of cutting force is imperative to understand the machinability and cutting mechanics of materials. The main 
Fig. 6 Variation of cutting force with three cutting parameters. a $\mathrm{Mg} / \mathrm{TiB}_{2}$ MMCs. b $\mathrm{Mg} / \mathrm{Ti}$ MMCs (a)

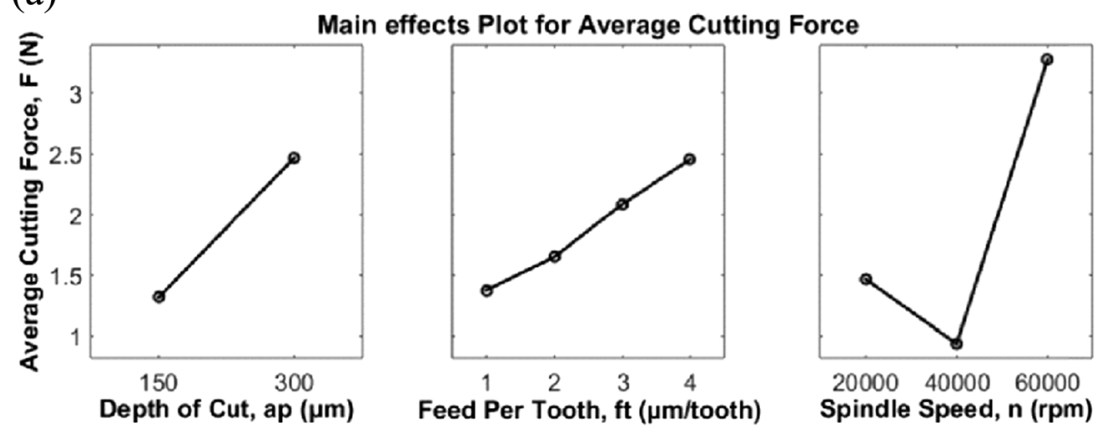

(b)

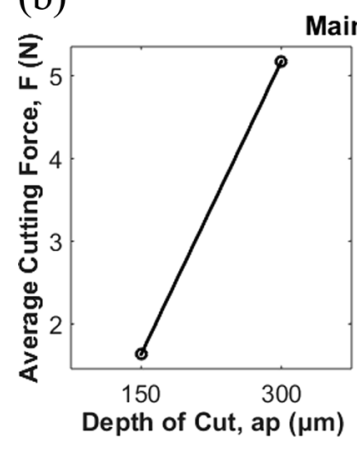

Main effects Plot for Average Cutting Force
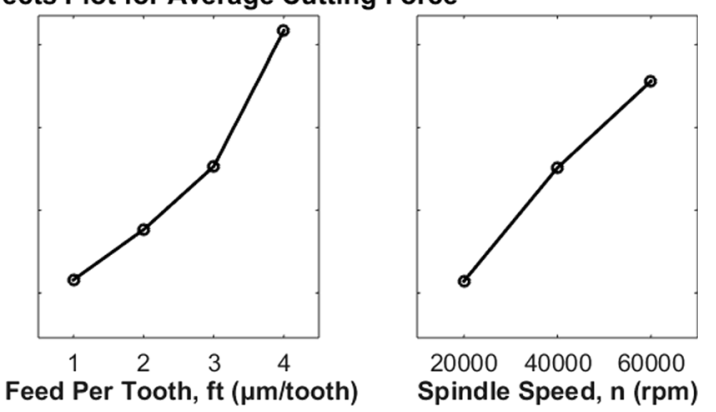

effect of three cutting parameters on the average cutting force of Fx and Fy in machining of two types materials is illustrated in Fig. 6.

The average cutting force can be observed to be increased by increasing both feed per tooth and depth of cut in both $\mathrm{Mg} / \mathrm{TiB}_{2}$ and $\mathrm{Mg} / \mathrm{Ti}$ MMCs. This is because more resistance is acted on the cutting tool due to the increased cross sectional area of chip and therefore leads to higher machining force with vibration which facilitates higher surface roughness. Additionally, it can be seen that the cutting force for $\mathrm{Mg} / \mathrm{Ti} \mathrm{MMCs}$ are more sensitive with the variation of depth of cut and feed per tooth compared to $\mathrm{Mg} / \mathrm{TiB}_{2}$.

For $\mathrm{Mg} / \mathrm{TiB}_{2} \mathrm{MMCs}$, the cutting force decreases when the spindle speed increase from 20,000 to $40,000 \mathrm{rpm}$ until a minimum value achieved, and a rapid increase in the cutting force is followed with the increasing of spindle speed from 40 , 000 to $60,000 \mathrm{rpm}$. But for $\mathrm{Mg} / \mathrm{Ti} \mathrm{MMCs}$ when spindle speed increase from 20,000 to $60,000 \mathrm{rpm}$, there is an approximate linear increase in the average cutting force from 2 to $4.5 \mathrm{~N}$. Same tendency can be obtained in the variation of surface roughness with spindle speed for both MMCs. The strength of materials could be dominated by two factors which are temperature and strain rate. For cutting $\mathrm{Mg}$ / $\mathrm{TiB}_{2}$ MMCs, the material strength and cutting force would decrease due to the thermal softening of the material at spindle speed from 20,000 to $40,000 \mathrm{rpm}$. However, the strength of materials would increase with strain rate during fast cutting speed. It was found that the strain strengthening becomes more dominant than thermal softening when spindle speed increased from 40,000 to $60,000 \mathrm{rpm}$. During cutting $\mathrm{Mg} / \mathrm{Ti} \mathrm{MMCs}$,

Table 5 ANOVA for surface roughness of $\mathrm{Mg} / \mathrm{TiB}_{2} \mathrm{MMCs}$

\begin{tabular}{|c|c|c|c|c|c|c|}
\hline Source of variation & $\begin{array}{l}\text { Degree of } \\
\text { freedom }\end{array}$ & $\begin{array}{l}\text { Sum of square } \\
\left(\times 10^{-3}\right)\end{array}$ & $\begin{array}{l}\text { Mean of square } \\
\left(\times 10^{-3}\right)\end{array}$ & $F$ value & $P$ value & $\%$ Contribution \\
\hline$n$ & 2 & 18.094 & 9.047 & 10.87 & 0.01 & $33 \%$ \\
\hline$a_{p}$ & 1 & 15.794 & 15.794 & 18.97 & 0.005 & $29 \%$ \\
\hline$f_{z}$ & 3 & 12.079 & 4.026 & 4.84 & 0.048 & $22 \%$ \\
\hline$n$ and $a_{p}$ & 2 & 0.624 & 0.312 & 0.37 & 0.702 & $1 \%$ \\
\hline$n$ and $f_{z}$ & 6 & 6.776 & 1.129 & 1.36 & 0.36 & $12 \%$ \\
\hline$f_{z}$ and $a_{p}$ & 3 & 1.397 & 0.466 & 0.56 & 0.661 & $3 \%$ \\
\hline Error & 6 & 4.994 & 0.832 & & & \\
\hline Total & 23 & 59.757 & & & & \\
\hline
\end{tabular}


Table 6 ANOVA for surface roughness of $\mathrm{Mg} / \mathrm{Ti} \mathrm{MMCs}$

\begin{tabular}{lllllll}
\hline Source of variation & Degree of freedom & $\begin{array}{l}\text { Sum of square } \\
\left(\times 10^{-3}\right)\end{array}$ & $\begin{array}{l}\text { Mean of square } \\
\left(\times 10^{-3}\right)\end{array}$ & $F$ value & $P$ value & $\%$ Contribution \\
\hline$n$ & 2 & 8.146 & 4.073 & 9.06 & 0.015 & $19 \%$ \\
$a_{p}$ & 1 & 20.709 & 20.709 & 46.06 & 0.001 & 0.064 \\
$f_{z}$ & 3 & 5.64 & 1.88 & 4.18 & 0.039 & $13 \%$ \\
$n$ and $a_{p}$ & 2 & 5.269 & 2.634 & 5.86 & 0.711 & $4 \%$ \\
$n$ and $f_{z}$ & 6 & 1.677 & 0.279 & 0.62 & 0.491 & $3 \%$ \\
$f_{z}$ and $a_{p}$ & 3 & 1.225 & 0.408 & & & \\
Error & 6 & 2.698 & 045 & & & \\
Total & 23 & 0.045363 & & &
\end{tabular}

strain strengthening might play the dominant role in determining strength of the material. Mg/Ti MMCs may present greater strain rate sensitivity than $\mathrm{Mg}$ / $\mathrm{TiB}_{2}$ and other aluminium-based MMCs. Lower level of spindle speed and feed per tooth therefore should be selected to minimise the cutting force while improving the machined surface quality. However, it is important to note that, the feed per tooth should not be smaller than the minimum uncut chip thickness otherwise cutting edge size effect would cause ploughing action governing the cutting process, which would deteriorate surface generation. Size effect will be discussed in the next section.

Figure 7 shows the comparison in the variation of cutting force with feed per tooth between $\mathrm{Mg} / \mathrm{TiB}_{2}$ and $\mathrm{Mg} / \mathrm{Ti} \mathrm{MMCs}$ at constant depth of cut of $150 \mu \mathrm{m}$, spindle speed of 40 , $000 \mathrm{rpm}$. The cutting force for the $\mathrm{Mg} / \mathrm{Ti} \mathrm{MMCs}$ is much higher than that for $\mathrm{Mg} / \mathrm{TiB}_{2}$. This can be attributed by the aforementioned chip adherence effect.

The mechanistic model proposed by Budak et al. [32] was utilised to determine the cutting constants and to generate the simulated cutting force during the micro-milling of $\mathrm{Mg} / \mathrm{TiB}_{2}$

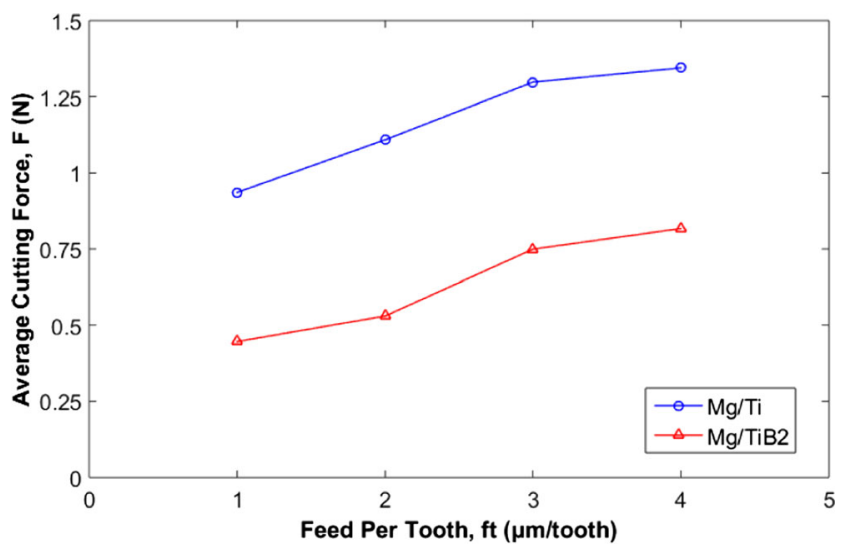

Fig. 7 The influence of reinforcement material on average cutting force at spindle speed: 40,000 rpm, depth of cut: $150 \mu \mathrm{m}$ and $\mathrm{Mg} / \mathrm{Ti}$ MMCs. The average cutting force in the $\mathrm{X}, \mathrm{Y}$ direction was determined as shown in Eqs. (1) and (2).

$$
\begin{gathered}
\overline{F_{x}}=\left\{\frac{N a_{p} f_{z}}{8 \pi}\left[K_{t c}(2 \varnothing-\sin 2 \varnothing)+K_{r c} \cos 2 \varnothing\right]-\frac{N a_{p}}{2 \pi}\left[K_{t e} \cos \varnothing+K_{r e} \sin 2 \varnothing\right]\right\}_{\varnothing_{s t}}^{\varnothing_{e x}} \\
\overline{F_{y}}=\left\{\frac{N a_{p} f_{z}}{8 \pi}\left[K_{\mathrm{tc}} \cos 2 \varnothing-K_{\mathrm{rc}}[2 \varnothing-\sin 2 \varnothing]\right]+\frac{N a_{p}}{2 \pi}\left[-K_{\mathrm{te}} \sin \varnothing+K_{\mathrm{re}} \cos 2 \varnothing\right]\right\}_{\varnothing_{\text {st }}}^{(1)} \\
x: \text { cross feed direction; } \quad y: \text { feed direction }
\end{gathered}
$$

Where $N$ is number of flutes of endmill, $K_{\mathrm{rc}}$ and $K_{\mathrm{tc}}$ are the cutting constants contributing to shearing action, $K_{\text {re }}$ and $K_{\text {te }}$ are cutting constants contributing to the ploughing action, $\varnothing$ is tool rotation angle, $f_{z}$ is the feed per tooth, $a_{p}$ is the axial depth of cut (edge contact length). For the full slot milling, the entry and exit angle are $\varnothing_{s t}=0$ and $\varnothing_{e x}=180^{\circ}$, respectively. When above conditions are applied to Eqs. 1 and 2, the average forces per tooth pass can be obtained as follows:

$\overline{F_{x}}=-\frac{N a_{p}}{4} K_{\mathrm{rc}} f_{z}-\frac{N a_{p}}{\pi} K_{\mathrm{re}}$
$\overline{F_{y}}=+\frac{N a_{p}}{4} K_{\mathrm{tc}} f_{z}+\frac{N a_{p}}{\pi} K_{\mathrm{te}}$

As a result, the value of cutting constants $\left(K_{\mathrm{rc}}, K_{\mathrm{re}}\right.$, $\left.K_{\text {tc }}, K_{\text {te }}\right)$ can be obtained by fitting above equations into average cutting force curve with feed per tooth.

Extra set of experiments (first experiment) on $\mathrm{Mg} / \mathrm{TiB}_{2}$ MMCs with feed per tooth of 3 and $4 \mu \mathrm{m} /$ tooth, depth of cut of $300 \mu \mathrm{m}$ and spindle speed of 40,000 rpm were conducted to perform the verification. The comparison between the simulated and measured cutting force in feed and normal direction are shown in Fig. 8. The prediction force shows a good agreement with the measured force for $F x$ at both levels of feed per tooth. In terms of the maximum cutting force, the error of prediction cutting force is $3-4 \%$ in $F x$ and $45-65 \%$ in $F y$ at 3 and $4 \mu \mathrm{m} /$ tooth. The difference in the maximum value of measured cutting forces generated from two tool pass in each period can be attributed to the non-uniformity existing in the geometries of two cutting edges. 

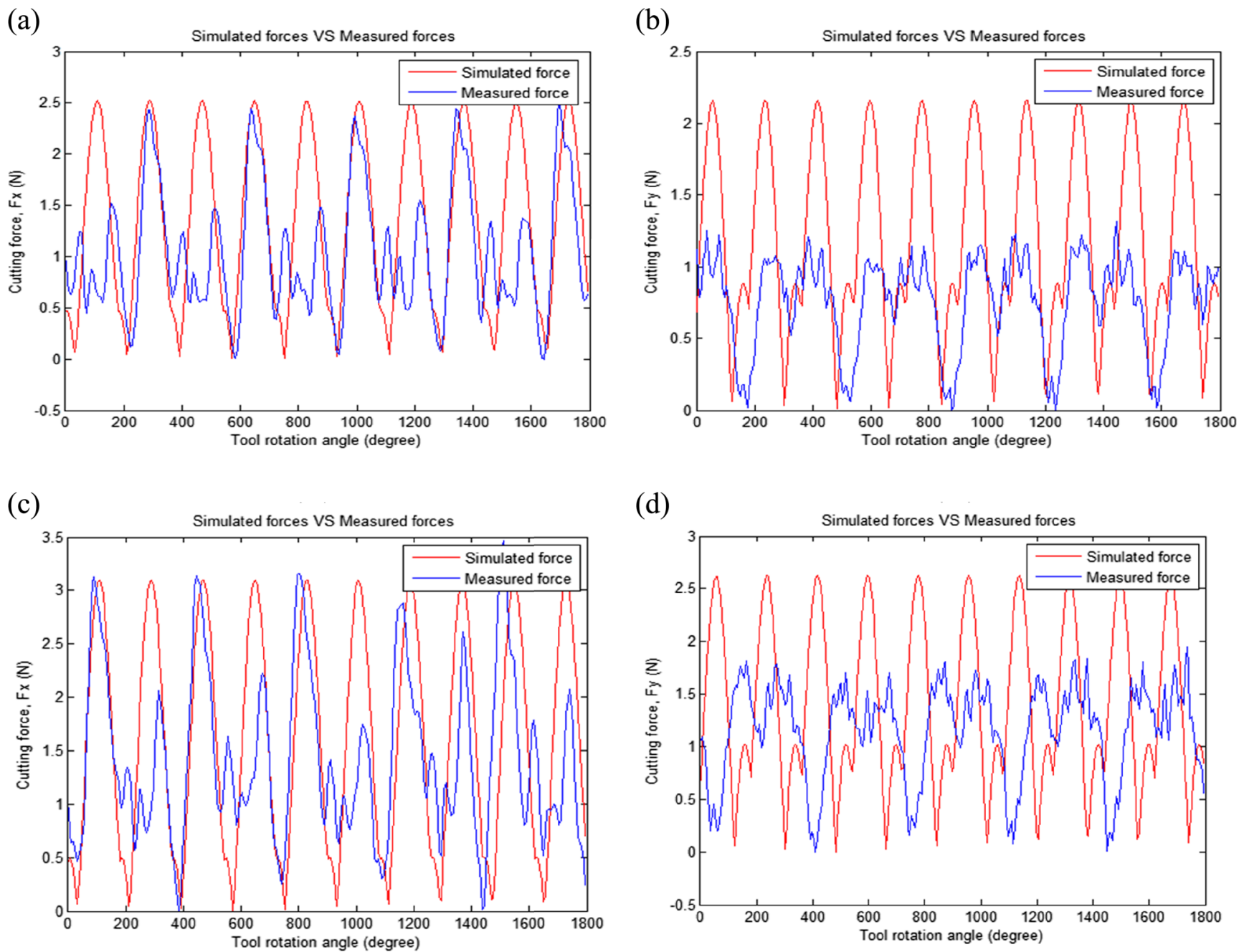

Fig. 8 Comparison of simulated and experimental measured cutting force for machining $\mathrm{Mg} / \mathrm{TiB}_{2}$ MMCs at depth of cut: $300 \mu \mathrm{m}$, spindle speed: 40,000 rpm; feed per tooth: $3 \mu \mathrm{m} /$ tooth a cutting force in cross

feed direction, $F x$; $\mathbf{b}$ cutting force in feed direction, $F y$ and at feed per tooth of $4 \mu \mathrm{m} /$ tooth; $\mathbf{c}$ cutting force in cross feed direction, $F x$; $\mathbf{d}$ cutting force in feed direction, $F y$

\subsection{Size effect}

\subsubsection{Mechanism of cutting edge radius size effect}

Although macro machining and micromachining can be considered kinematically similar, there are a number of fundamental differences existing between them. With the decreasing of uncut chip thickness which is dimensionally close to the cutting edge radius of the cutting tool, size effect becomes a dominant factor that leads to a transitional regimes associated with intermittent shearing and ploughing during the machining [33]. The material could be ploughed off, and elastic deformation would become the dominant cutting regime when the uncut chip thickness is below a critical value, chip may not be formed during each tool path which would deteriorate the surface [34-36] (as illustrated in Fig. 9). Essentially, the size effect can lead to a negative effect on the cutting process

such as higher cutting force, premature tool breakage, and worse machined surface quality.

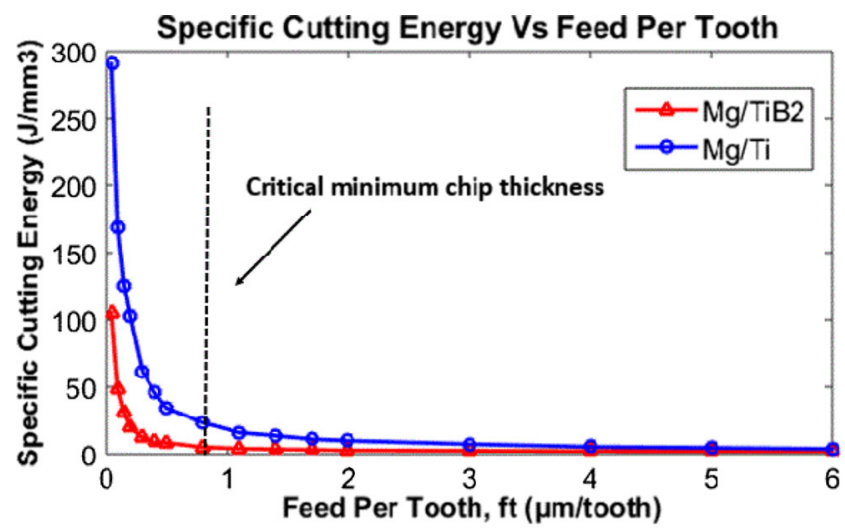

Fig. 9 Specific cutting energy of $\mathrm{Mg} / \mathrm{TiB}_{2}$ and $\mathrm{Mg} / \mathrm{Ti} \mathrm{MMCs}$ obtained at spindle speed: $40,000 \mathrm{rpm}$, depth of cut: $200 \mu \mathrm{m}$ 
In this study, the investigation of size effect was carried out according to two aspects which are specific cutting energy and surface morphology, and the value of minimum chip thickness for such materials were determined.

\subsubsection{Specific cutting energy}

Specific cutting energy can be defined as the energy consumed in removing a unit volume of material. The specific cutting energy for each material is calculated through expression (5), where $F x$ and $F y$ are the cutting force component in $\mathrm{X}$ and $\mathrm{Y}$ direction, $v_{c}$ is the cutting speed in $\mathrm{m} / \mathrm{min}, V_{\text {rem }}$ is removed chip volume, $t_{c}$ is the cutting time.

$u_{c}=\frac{v_{c}}{V_{\mathrm{rem}}} \int_{0}^{t_{c}} \sqrt{F x^{2}+F y^{2}} d t$

Figure 9 shows the variation of the specific cutting energy with feed per tooth for $\mathrm{Mg} / \mathrm{TiB}_{2}$ and $\mathrm{Mg} / \mathrm{Ti}$ MMCs at a spindle speed of $40,000 \mathrm{rpm}$ and a depth of cut of $200 \mu \mathrm{m}$. Size effect can be observed according to the non-linear decrease of the specific cutting energy with feed per tooth. As illustrated in Fig. 9, as the ratio of feed per tooth to the cutting edge radius increases, the specific cutting energy decreases rapidly, and transits to a stable value at the feed per tooth between 1 and $2 \mu \mathrm{m} /$ tooth. The high specific cutting energy at small feed was attributed to that the material undergo an elastic deformation and deformed material fully recovers to its original position, as a consequence an uneven distribution of stress is caused by the interaction of workpiece and cutting tool. A transition for the specific cutting energy approaching to a stable value is expected at where the feed per tooth is close to the critical uncut chip thickness. Finally, when the feed per tooth is larger than the critical chip thickness, the material deforms plastically by shearing, and continuous chips are formed. In addition, by comparing these two materials, it can be reported that much more energy is required to cut $\mathrm{Mg} / \mathrm{Ti} \mathrm{MMC}$ than $\mathrm{Mg} / \mathrm{TiB}_{2}$ when the feed per tooth is below the critical value. This leads to a worse machined slot edge for $\mathrm{Mg} / \mathrm{Ti}$ MMCs with more burrs as shown in Fig. 10.

\subsubsection{Machined surface morphology}

Observation of machined surface in Fig. 10 revealed that for both $\mathrm{Mg} / \mathrm{TiB}_{2}$ and $\mathrm{Mg} / \mathrm{Ti} \mathrm{MMCs}$, various types of surface defects were formed during machining. Severe top burr formation, worse surface and large area of cracks were observed on the slot edges and machined surfaces at small feed per tooth of 0.15 and $0.3 \mu \mathrm{m} /$ tooth (example are Fig. 10a, b, e, f, k). The burr formed during machining process considerably affect not only the dimensional accuracy and functionality of produced product but also tool wear due to the size of burr approaching to half of slot width at small feed per tooth. However, the amount of burrs on the slots and cracks formed decreases when the feed per tooth increases from 0.3 to $0.8 \mu \mathrm{m} /$ tooth, and a machined surface without burrs and surface defects was obtained at feed per tooth of 0.8 (example are Fig. 10d, $\mathrm{h}, \mathrm{j}$ ). The materials toward the cutting direction was squeezed and therefore deformed plastically at small feed per tooth when ploughing took place instead of shearing action. Then partial of fractured materials remained at slot edges and burrs were formed.

The results shows an excellent agreement with the findings that higher forces incurred in small feed per tooth due to size effect may result in high value of surface roughness as well as the worse surface quality. It can also be seen from Fig. 10 that the material in the same position was cut more than once, which results in overlapping tool marks generated on the surface and indicates that the material was elastically ploughed off due to the size effect. Therefore, based on all the work done in this paper the minimum chip thickness for cutting $\mathrm{Mg} / \mathrm{TiB}_{2}$ and $\mathrm{Mg} / \mathrm{Ti}$ MMCs can be determined as $0.8 \mu \mathrm{m}$ and the ratio of minimum chip thickness and cutting edge radius is approximately as $53 \%$, which is relatively large than that of pearlite $(20 \%)$ and ferrite (35\%) steel [35].e

By comparing the two Mg MMCs, more top burrs on slot edges and worse surface quality with evenly distributed crack on the surface were found $\mathrm{Mg} / \mathrm{Ti} \mathrm{MMC}$. As the reinforcement material, titanium and its alloy exhibit low thermal conductivity, high ductility and adhesion. These characteristics and strain hardening of composite materials lead to adhesion and high burr formation during micromachining. Meanwhile, the thermal softening of both matrix and reinforcement materials caused by high temperature also facilitate this phenomenon. As a result, large and continuous burr was formed along the slot edges.

As MMCs materials are more brittle than the monolithic metals, it is very sensitive to impact at the moment which the material and tool come into contact, therefore the uncut chip thickness starts from zero and gradually increases to the maximum, so less burrs were formed at the up milling side according to Fig. 10b, g, h. Additionally, it can be seen from Fig. 10f that a more defective slot edge could be generated at down milling side compared to that at up milling side. The cutting direction and the tool feed direction is opposite in both up and down milling; therefore, the characteristics is 


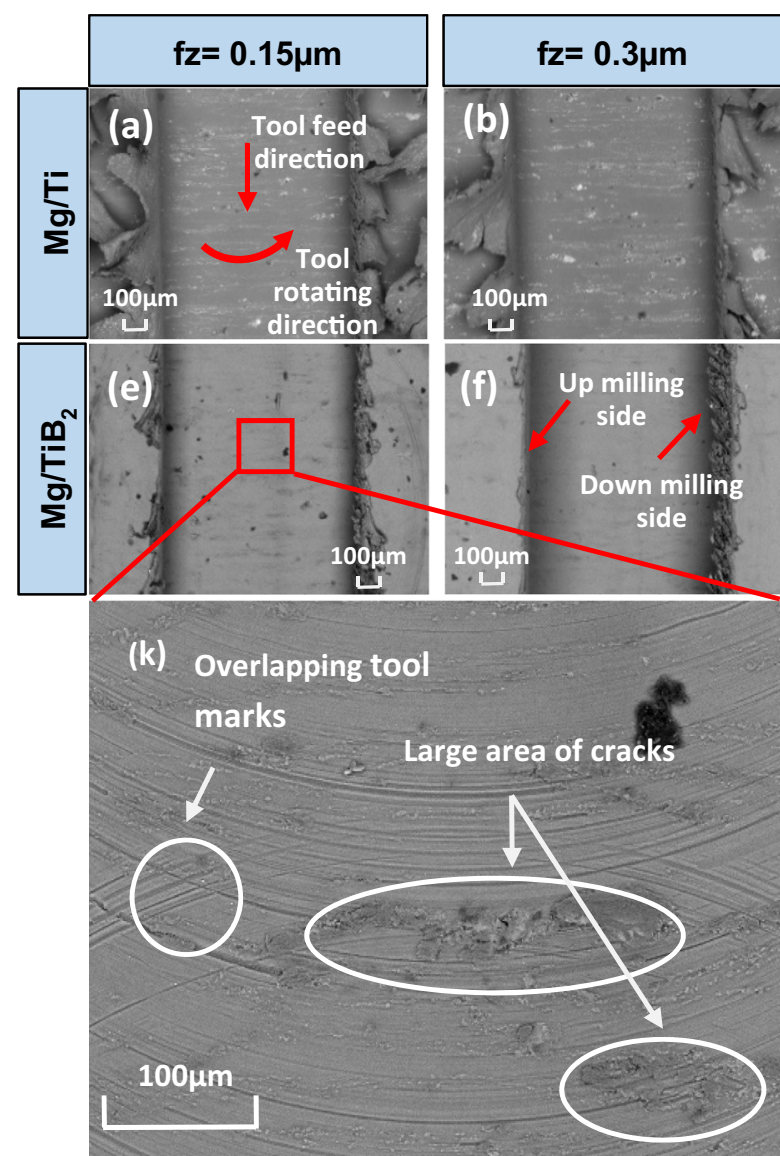

Fig. $10 \mathrm{SEM}$ micrographs of micromachined slots for $\mathrm{Mg} / \mathrm{TiB}_{2} \mathrm{MMCs}$ and Mg/ Ti MMCs at spindle speed: 40,000 rpm depth of cut: $200 \mu \mathrm{m}$ a and $\mathbf{e}$ feed per tooth: $0.15 \mu \mathrm{m} /$ tooth; $\mathbf{b}$ and $\mathbf{f}$ feed per tooth: $0.3 \mu \mathrm{m} /$ tooth;

different in surface and burr formation in the up milling and down milling [37].

\section{Conclusions}

A comprehensive study on micro-machinability of magnesium-based metal matrix composites reinforced with nano-sized titanium (Ti) and titanium diboride $\left(\mathrm{TiB}_{2}\right)$ was performed by micro-end milling process using AlTiN-coated carbide end mills. The effect of reinforcement materials and volume fraction on the tool wear and its mechanism was studied. The cutting force was analysed and a mechanistic model as established. Additionally, the machined surface were characterised in terms of the surface morphology and surface roughness. Also, the size effect was investigated and minimum chip thickness was obtained according to specific cutting energy and surface morphology. The following conclusions can be drawn from this work:

- Chip adhesion effect was found to be more evident during the machining of MMCs with nano-sized Ti particles

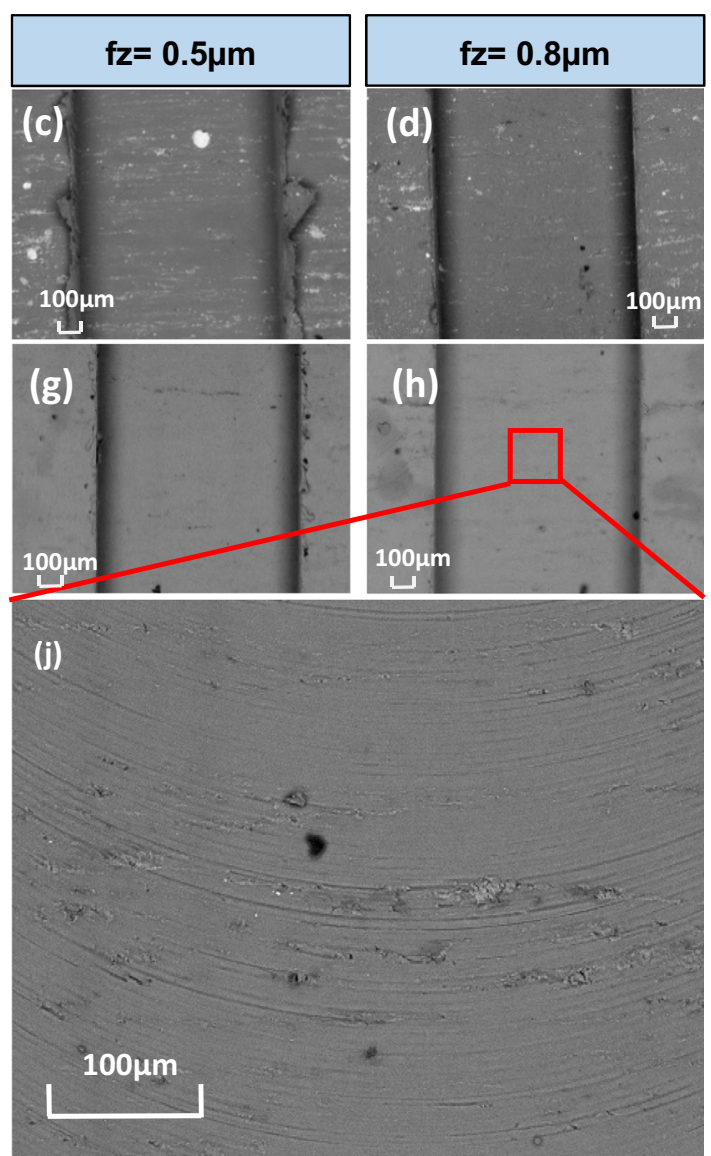

$\mathbf{c}$ and $\mathbf{g}$ feed per tooth: $0.5 \mu \mathrm{m} /$ tooth; $\mathbf{d}$ and $\mathbf{h}$ feed per tooth: $0.8 \mu \mathrm{m} /$ tooth. $\mathbf{k}$ Magnified image of $\mathbf{e} ; \mathbf{j}$ magnified image of $\mathbf{h}$

when compared to $\mathrm{TiB}_{2}$ particles, due to the ductile structure of matrix $(\mathrm{Mg})$ and reinforcement material (Ti). Consequently, high cutting force, worse surface and more burrs were induced. Coating peeling off was observed in the machining of $\mathrm{Mg} / \mathrm{TiB}_{2} \mathrm{MMCs}$. Both high mechanical and thermal load can be characterised as the main factors that contribute to this phenomenon. Moreover, it is found that the severity of coating peeling off would increase with the increase of volume fraction of reinforcements.

- The cutting force would increase with the depth of cut and feed per tooth which is larger than the minimum chip thickness. An approximate two times larger cutting force was obtained in the machining of $\mathrm{Mg} / \mathrm{Ti} \mathrm{MMC}$ compared to that for $\mathrm{Mg} / \mathrm{TiB}_{2}$. The surface roughness would rise with the increase of feed per tooth and spindle speed, but the trend with depth of cut were opposite on cutting two MMCs. Based on the ANOVA, the spindle speed and depth of cut has significant influence on surface roughness.

- The minimum chip thickness is determined to be $0.8 \mu \mathrm{m}$ which is $53 \%$ of the cutting edge radius in this experiment. Essentially, for machining $\mathrm{Mg} / \mathrm{Ti}$ and $\mathrm{TiB}_{2}$ MMCs 
feed per tooth under minimum chip thickness is not recommended.

- The $\mathrm{Mg} / \mathrm{TiB}_{2}$ MMCs exhibit better machinability compared to $\mathrm{Mg} / \mathrm{Ti} \mathrm{MMCs}$ in terms of surface morphology. More burrs could be found at slot edges after machining $\mathrm{Mg} / \mathrm{Ti}$ MMCs. Up milling side could generate slot edges with better quality and less burrs in machining of $\mathrm{Mg} / \mathrm{Ti}$ MMCs.

Acknowledgments The authors wish to thank EPSRC (EP/M020357/ 1) for the support of this work. The authors are also grateful for Mr Brian Stoker at Newcastle University for his assistance in the work.

Open Access This article is distributed under the terms of the Creative Commons Attribution 4.0 International License (http:// creativecommons.org/licenses/by/4.0/), which permits unrestricted use, distribution, and reproduction in any medium, provided you give appropriate credit to the original author(s) and the source, provide a link to the Creative Commons license, and indicate if changes were made.

\section{References}

1. Beck AV (1943) The technology of magnesium and its alloys. F.A. Hughes \& co. limited, London

2. Monaghan JM (1996) The use of a quick-stop test to study the chip formation of a SiC/Al metal matrix composite material and its matrix alloy. Int J Fatigue 3:213-217

3. Dieringa H (2010) Properties of magnesium alloys reinforced with nanoparticles and carbon nanotubes: a review. J Mater Sci 46:289-306

4. Ferguson JB (2012) On the strength and strain to failure in particlesreinforced magnesium metal matrix nanocompostes $(\mathrm{Mg}$ MMNCs). Mater Sci Eng A 558:193-204

5. Tjong SC (2007) Novel nanoparticle-reinforced metal matrix composites with enhanced mechanical properties. Adv Eng Mater 9: 639-652. doi:10.1002/adem.200700106

6. Wang HY, Jiang QC, Li XL, Wang JG, Guan QF, Liang HQ (2003) In situ synthesis of TiC from nanopowders in a molten magnesium alloy. Mater Res Bull 38:1387-1392

7. Li WJ, Tu R, Goto T (2006) Preparation of directionally solidified TiB2-TiC eutectic composites by a floating zone method. Mater Lett 60:839-843

8. Wen G, Li SB, Zhang BS, Guo ZX (2001) Reaction synthesis of TiB2-TiC composites with enhanced toughness. Acta Mater 49: $1463-1470$

9. Dean S, Zhang X, Wang H, Liao L, Ma N (2006) New synthesis method and mechanical properties of magnesium matrix composites. J ASTM Int 3:13036

10. Pérez P, Garcés G, Adeva P (2004) Mechanical properties of a Mg10 (vol.\%)Ti composite. Compos Sci Technol 64:145-151

11. Kumar SS, Uthayakumar M, Kumaran ST, Parameswaran P (2014) Electrical discharge machining of $\mathrm{Al}(6351)-\mathrm{SiC}-\mathrm{B} 4 \mathrm{C}$ hybrid composite. Mater Manuf Process 29:1395-1400. doi:10.1080/ 10426914.2014.952024

12. Müller F, Monaghan J (2000) Non-conventional machining of particle reinforced metal matrix composite. Int $\mathrm{J}$ Mach Tools Manuf 40:1351-1366

13. Kannan S, Kishawy HA, Deiab I (2009) Cutting forces and TEM analysis of the generated surface during machining metal matrix composites. J Mater Process Technol 209:2260-2269. doi:10. 1016/j.jmatprotec.2008.05.025
14. Du J, Zhou L, Li J, Yao Y (2014) Analysis of chip formation mechanism in mill-grinding of $\mathrm{SiCp} / \mathrm{Al}$ composites. Mater Manuf Process 29:1353-1360. doi:10.1080/10426914.2014.912309

15. Aurich JC, Zimmermann M, Schindler S, Steinmann P Effect of the cutting condition and the reinforcement phase on the thermal load of the workpiece when dry turning aluminum metal matrix composites. Int J Adv Manuf Technol. doi: 10 . 1007/s00170-015-7444-0

16. Weinert K, Lange M (2001) Machining of magnesium matrix composites. Adv Eng Mater 3:975-979. doi:10.1002/15272648(200112)3:12<975::AID-ADEM975>3.0.CO;2-L

17. Takács M, Verö B, Mészáros I (2003) Micromilling of metallic materials. J Mater Process Technol 138:152-155

18. Ciftci I, Turker M, Seker U (2004) CBN cutting tool wear during machining of particulate reinforced MMCs. Wear 257:1041-1046. doi:10.1016/j.wear.2004.07.005

19. Ciftci I, Turker M, Seker U (2004) Evaluation of tool wear when machining SiCp-reinforced Al-2014 alloy matrix composites. Mater Des 25:251-255. doi:10.1016/j.matdes.2003.09.019

20. Huang ST, Zhou L, Chen J, Xu LF (2012) Drilling of SiCp/Al metal matrix composites with polycrystalline diamond (PCD) tools. Mater Manuf Process 27:1090-1094. doi:10.1080/10426914. 2011.654152

21. Muguthu JN, Dong G, Ikua B (2013) Optimization of machining parameters influencing machinability of A12124SiCp (45\%wt) metal matrix composite. J Compos Mater 49:217-229. doi:10.1177/ 0021998313516141

22. PalDey S, Deevi S (2003) Single layer and multilayer wear resistant coatings of (Ti, Al)N: a review. Mater Sci Eng A 342:58-79. doi:10. 1016/S0921-5093(02)00259-9

23. Bouzakis KD, Michailidis N, Skordaris G et al (2012) Cutting with coated tools: coating technologies, characterization methods and performance optimization. CIRP Ann Manuf Technol 61:703723. doi:10.1016/j.cirp.2012.05.006

24. Cheng K, Huo D (2013) Micro-cutting: fundamental and application. John Wiley \& Sons Ltd, Chichester

25. Liu J, Li J, Xu C (2013) Cutting force prediction on micromilling magnesium metal matrix composites with nanoreinforcements. J Micro Nano-Manuf 1:011010

26. Wong W, Gupta M (2015) Using microwave energy to synthesize light weight/energy saving magnesium based materials: a review. Technologies 3:1-18

27. Filiz S, Conley CM, Wasserman MB, Ozdoganlar OB (2007) An experimental investigation of micro-machinability of copper 101 using tungsten carbide micro-endmills. Int J Mach Tools Manuf 47:1088-1100

28. Ucun I, Aslantas K, Bedir F (2013) An experimental investigation of the effect of coating material on tool wear in micro milling of Inconel 718 super alloy. Wear 300:8-19. doi:10.1016/j.wear.2013.01.103

29. Yanming Q, Zehua Z (2000) Tool wear and its mechanism for cutting $\mathrm{SiC}$ particle-reinforced aluminium matrix composites. J Mater Process Technol 100:194-199. doi:10.1016/S09240136(99)00405-7

30. Kumar A, Mahapatra MM, Jha PK (2014) Effect of machining parameters on cutting force and surface roughness of in situ Al$4.5 \% \mathrm{Cu} / \mathrm{TiC}$ metal matrix composites. Meas $\mathrm{J}$ Int Meas Confed 48:325-332. doi:10.1016/j.measurement.2013.11.026

31. Suresh Kumar Reddy N, Kwang-Sup S, Yang M (2008) Experimental study of surface integrity during end milling of $\mathrm{Al} / \mathrm{SiC}$ particulate metal-matrix composites. J Mater Process Technol 201:574-579. doi:10.1016/j.jmatprotec. 2007.11.280

32. Budak E, Altintaş Y, Armarego EJA (1996) Prediction of milling force coefficients from orthogonal cutting data. J Manuf Sci Eng 118:216 
33. Liu X, Devor RE, Kapoor SG, Ehmann KF (2004) The mechanics of machining at the microscale: assessment of the current state of the science. J Manuf Sci Eng 126:666

34. Kim CJ, Bono M, Ni J (2002) Experimental analysis of chip formation in micro-milling. Soc Manuf Eng 30:1-8

35. Vogler MP, Devor RE, Kapoor SG (2004) On the modeling and analysis of machining performance in micro-endmilling, part i: surface generation. J Manuf Sci Eng 126:685-694
36. Weule H, Hüntrup V, Tritschler H (2001) Micro-cutting of steel to meet new requirements in miniaturization. CIRP Ann Manuf Technol 50:61-64

37. Liu J, Li J, Xu C (2014) Interaction of the cutting tools and the ceramic-reinforced metal matrix composites during micro-machining: a review. CIRP J Manuf Sci Technol 7:5570. doi:10.1016/j.cirpj.2014.01.003 